\title{
Local privilegiado para a formação de professores: arquitetura e espaços de um Instituto de Educação ${ }^{1}$
}

\author{
Aline de Novaes Conceição² \\ Macioniro Celeste Filho ${ }^{3}$
}

\begin{abstract}
Resumo
Neste artigo, há resultados de um estudo sobre a arquitetura e os espaços do extinto Instituto de Educação "Fernando Costa". Com o objetivo de compreender a organização desse IE, especificamente a configuração arquitetônica e os espaços desse prédio, entre 1953 e 1975, período de funcionamento dessa instituição, foi utilizada pesquisa bibliográfica e documental com abordagem histórica tendo como fontes a planta dessa instituição e imagens do prédio do IE em questão. Para análise das fontes, considera-se o paradigma indiciário, visando localizar indícios que possibilitassem reconstituir aspectos da realidade buscada. Conclui-se que no prédio em que funcionou o IE "Fernando Costa" há o predomínio do retílineo, andares e escadas, além disso, esse prédio representa a grandiosidade.

Palavras-chave: Arquitetura e espaços de Instituições Educativas; Instituto de Educação; Instituições Educativas; Educação em Presidente Prudente/SP; História da Educação.
\end{abstract}

\section{Privileged place for teacher education: architecture and spaces of an Institute of Education}

\begin{abstract}
In this article, there are results of a study on the architecture and spaces of the extinct Institute of Education "Fernando Costa". In order to understand the organization of this IE, specifically the architectural configuration and the spaces of this building, between 1953 and 1975, the period of operation of this institution, was used a bibliographical and documentary research with historical approach having as sources the plant of this institution and images of the IE building in question. For the analysis of the sources, the indiciary paradigm is considered, aiming to locate clues that make it possible to reconstitute aspects of the reality sought. It can be concluded that in the building where IE "Fernando Costa" operated, there is a predominance of lining, floors and stairs, besides, this building represents grandeur.

Keywords: Architecture and spaces of Educational Institutions; Institute of Education; Educational Institutions; Education in Presidente Prudente / SP; History of Education.
\end{abstract}

\section{Introdução}

O Dicionário de Arquitetura (2015, p.7) define-a como a "Arte de construir edifícios para qualquer finalidade, tendo em vista o conforto humano, a realidade social e o sentido plástico

\footnotetext{
${ }^{1}$ Este trabalho resulta de dissertação (CONCEIÇÃO, 2017).

2 Universidade Estadual Paulista (Unesp), “Júlio de Mesquita Filho", Faculdade de Filosofia e Ciências (FFC), Marília/SP. Endereço eletrônico: alinenovaesc@gmail.com

${ }^{3}$ Unesp-FFC-Marília/SP. Endereço eletrônico: marciocelestefilho@gmail.com
}

Periódico Horizontes - USF - Itatiba, SP - Brasil - e019049 
da época em que se vive." Em relação ao espaço, é possível constatar que as atividades humanas necessitam de espaço e tempo determinados: o espaço é pensado, enquanto que o lugar é construído. Nessa perspectiva, a compreensão do espaço está relacionada com a atividade humana (FRAGO, 2001, p.64)

(...) o espaço jamais é neutro: em vez disso, ele carrega, em sua configuração como território e lugar, signos, símbolos e vestígios da condição e das relações sociais de e entre aqueles que o habitam. $O$ espaço comunica; mostra a quem sabe ler, o emprego que o ser humano faz dele mesmo.

Em relação à educação considera-se que a escola ocupa um espaço e ocupa um lugar, sendo que muitas vezes o espaço da escola não foi projetado para ser escola (FRAGO, 2001). O “(...) planejamento da localização dos edíficios escolares seria consequência, no século XX, tanto da introdução da escola seriada, como da política de construções escolares (...)" (FRAGO, 2001, p.88).

Segundo Vidal e Faria Filho (2005, p.42) os espaços “(...) foram sendo produzidos diferencialmente ao longo da nossa história da educação (...)". Ao ocuparmos um tempo histórico em que as pessoas precisavam de formação para serem professores, ou seja, precisavam de uma formação específica para tal função, o espaço escolar também se tornou específico. Com isso, o espaço escolar não deveria ocupar qualquer local, mas deveria "(...) ser configurado de um modo definido e próprio, independente de qualquer outro, em um espaço também adequado para tal fim. Isso implicava seu isolamento ou separação. Também sua identificação arquitetônica enquanto tal." (FRAGO, 2001, p.73).

A partir da leitura do texto de Frago (2001), passei a buscar compreender o espaço do Instituto de Educação (IE) "Fernando Costa" da cidade de Presidente Prudente/SP4. Em 1932, os Institutos de Educação foram criados, por Anísio Teixeira no Rio de Janeiro (que nesse momento histórico era o Distrito Federal do país), durante a sua gestão enquanto Diretor da Instrução Pública. A partir dessa experiência no Distrito Federal, criou-se o primeiro IE do estado de São Paulo “(...) pelo decreto estadual no 5846, de 21 de fevereiro de 1933, promulgado na 'Reforma

\footnotetext{
${ }^{4}$ A escolha desse Instituto de Educação está relacionada com uma das funções dessa instituição que era de formar professores, além de serem "[...] escolas de excelência e ser formado por uma instituição como essa dava certo status ao professor." (LABEGALINI, 2009, p.16).
}

Periódico Horizontes - USF - Itatiba, SP - Brasil - e019049 
Fernando de Azevedo', sintetizada no Decreto estadual no 5884, de 21 de abril de 1933, o Código da Educação do Estado de São Paulo." (LABEGALINI, 2005, p.54-55, grifo do autor). Esse primeiro IE foi denominado de "Caetano de Campos" ${ }^{5}$, criado a partir da transformação da Escola Normal da Praça da República norteada pelo Decreto n.6.019, de 10 de agosto de 1933 (LABEGALINI, 2005).

Vale destacar que em 1933 "(...) só houve um IE criado nesse ano e o processo de expansão para o interior do estado e para o litoral iniciou-se apenas em 1951, havendo a criação de novos institutos de educação até 1967. Tais escolas permaneceram como IEs até 1975." (LABEGALINI, 2005, p.14).

Nas décadas posteriores à criação do Código de Educação do Estado de São Paulo de 1933, os IEs do estado de São Paulo foram expandidos pela transformação de "Escolas Normais", "Colégios Estaduais", "Ginásios Estaduais" em Institutos de Educação, os

(...) Os últimos IEs criados no estado de São Paulo datam de 1967 e todos os IEs do nosso estado deixaram de sê-los por determinação da Lei 5692/71; porém apesar de essa lei ser de 1971, a denominação "instituto de educação" persistiu até 1975, pois em 20 de janeiro de 1976 foi promulgado o Decreto Estadual 7510, que reorganizou a Secretaria do Estado da Educação, transformando todas as escolas públicas, inclusive os IEs estaduais, em Escola Estadual de $2 \stackrel{\circ}{\text { grau, ou }}$ ainda em Escola Estadual de 1ㅇe e 20 graus (LABEGALINI, 2005, p.88-89).

Dentre as definições do Código de Educação do Estado de São Paulo, de 1933, em relação ao Instituto de Educação destacava-se a importância em:

(...) formar professores primarios e secundarios e diretores e inspetores de escolas (...); ministrar ensino primario e secundário a alunos de ambos os sexos, em estabelecimentos que permitam a observação, a experimentação e a pratica de ensino, por parte dos candidatos ao professorado (SÃO PAULO, 1933, p.396, apud LABEGALINI, 2009, p.54).

Diante disso, tornam-se importantes os estudos sobre os Institutos de Educação, compreendendo-os como instituições complexas de ensino cujo eixo central era a formação de

\footnotetext{
${ }^{5}$ Nesse IE, havia as seguintes seções: educação, biologia educacional, psicologia educacional e prática de ensino, além disso, havia um centro de Psicologia experimental aplicada à educação que buscava determinar a "capacidade mental” da criança e divulgar princípios psicológicos relacionados ao aprendizado (LABEGALINI, 2005).
}

Periódico Horizontes - USF - Itatiba, SP - Brasil - e019049 
professores. Neste texto, como mencionei, selecionei o Instituto de Educação "Fernando Costa", buscando compreender especificamente o que está relacionado à sua configuração arquitetônica e a ordenação espacial. Assim, o objetivo que resultou na elaboração deste texto, consiste em compreender a organização do Instituto de Educação "Fernando Costa", especificamente a configuração arquitetônica e os seus espaços, no período entre 1953 e 1975 , que refere-se ao ano em que foi instalado o IE "Fernando Costa" e ano anterior da implementação no estado de São Paulo, da Reforma do Ensino de primeiro e segundo graus baseada na Lei n.5.692 de $1971^{6}$.

A “(...) Lei 5.692/71 apresenta dois pontos fundamentais: a extensão da escolaridade obrigatória, compreendendo agora todo o denominado ensino de 10 grau, junção do primário com o ginásio, e a generalização do ensino profissionalizante no nível médio ou 2ํ grau." (GERMANO, 2000, p.164), a partir dessa lei ocorreu a extinção dos IEs.

Para isso, utilizei pesquisa bibliográfica e documental com abordagem histórica e utilizei como fontes o inventário7 de 1965, do IE "Fernando Costa"; a planta dessa instituição; a imagem do IE na década de 40 e fotografias atuais dessa instituição, considerando que a fotografia é uma “(...) interpretação do real, a fotografia é um vestígio diretamente calcado sobre o real, como uma pegada" (BENCOSTTA, 2011, p.398).

Para analisar as fontes, considerei o "paradigma indiciário" explicitado por Ginzburg (1989) que consiste principalmente na "decifração de pistas", inclusive as pistas mudas e na "(...) capacidade de, a partir de dados aparentemente negligenciáveis, remontar a realidade complexa não experimentável diretamente." (GINZBURG, 1989, p.152). Esses dados são particularidades que como "pistas" possibilitam "(...) reconstruir trocas e transformações culturais." [pois...] a realidade é opaca, [mas] existem zonas privilegiadas - sinais, indícios - que permitem decifrála." (GINZBURG, 1989, p.177).

Como primeira etapa de uma investigação mais ampla, a origem do Instituto de Educação "Fernando Costa", em seguida, destaco a reflexão dos espaços desse IE, focalizando o exterior e

\footnotetext{
${ }^{6}$ Ressalto que a fim de implementar essa lei, a Secretaria de Estado da Educação “[...] dedicou-se a difusão das novas orientações legais da rede de ensino, capacitando mais de 150 mil professores, 5.000 diretores e grande número de supervisores, delegados de ensino e técnicos da Secretaria." (SOUZA, 2008, p.277).

7 Nesse inventário, há a descrição dos cômodos e dos materiais contidos em cada cômodo do IE "Fernando Costa", além disso, há a quantidade e os valores desses materiais.
}

Periódico Horizontes - USF - Itatiba, SP - Brasil - e019049 
o interior do prédio em que funcionou essa instituição.

\section{Instituto de educação "Fernando Costa": origem}

Em 1920, na cidade de Presidente Prudente/SP, foram fundadas as Escolas Reunidas (ENSINO, 2003). Em 1928, nessa cidade, não havia estabelecimento de ensino de nível médio, mas havia um Grupo Escolar (LITHOLDO, 1984) ${ }^{8}$. Esse Grupo Escolar foi nomeado de professor "Adolpho Arruda Mello" (RESENDE, 2006) e se instalou a partir da conversão das Escolas Reunidas $^{9}$ (PAULA et al., 2012).

Em 1929, o professor João Bohac escreveu dois artigos no jornal de Prudente/SP, mencionando a necessidade de criarem uma Escola Normal Livre na cidade, “(...) pedia tão somente a instalação de uma Escola Normal para resolver o problema da falta de professores para o curso primário" (LITHOLDO, 1984, p.17), pois não havia professores para o Grupo Escolar da cidade.

Um habitante de Presidente Prudente/SP, Boulanger Uchôa, advogado casado com a professora primária Dulce Uchôa, leu os artigos do professor Bohac, encontrou com ele e relatou seu desejo de criar, por iniciativa particular, um Curso Normal na cidade (que era tido como ensino de nível médio). Boulanger comprou um prédio localizado na Avenida Coronel Marcondes para instalação desse estabelecimento de ensino e criou um Curso Normal em Prudente/SP, denominado Colégio São Paulo (LITHOLDO, 1984).

Para a criação desse curso foram realizados exames de admissão em 1929, com 13 candidatos para contratação. Nessa ocasião, todos os candidatos foram aprovados e em 1930, “(...) deu-se o início do primeiro curso médio em Presidente Prudente. Juntamente com a Escola Normal Livre passaram a funcionar um curso de Guarda-Livros e o Curso Ginasial, embora esse último não estivesse ainda regularizado, oficialmente" (LITHOLDO, 1984, p.20).

Devido necessidades financeiras o Curso Normal foi extinto no final de 1930 e os “(...) demais cursos (ginasial e comercial) tiveram a sua continuação" (LITHOLDO, 1984, p.20); os treze

\footnotetext{
${ }^{8}$ Litholdo (1984) escreveu o livro A função educacional na alta sorocabana: uma contribuição à geografia urbana, o autor foi professor do Departamento de Geografia Humana e Regional da UNESP de Presidente Prudente/SP e entre 1971 a 1975, foi diretor dessa UNESP (GALERIA..., 2015).

${ }^{9}$ Por decreto de 22 de janeiro de 1925, essas escolas foram transformadas em Grupo Escolar (PAULA et al., 2012).
}

$$
\text { Periódico Horizontes - USF - Itatiba, SP - Brasil - e019049 }
$$


alunos matriculados na Escola Normal Livre puderam transferir seus estudos para serem realizados em outras Escolas Normais do Estado (LITHOLDO, 1984).

Em 1936, no mesmo prédio comprado por Boulanger, funcionou o Curso Ginasial denominado de Ginásio São Paulo. Assim, o primeiro ginásio da cidade era particular e foi instalado no Colégio São Paulo:

(...) localizado na Rua Dr. Gurgel no 860, em região bem central da cidade de Presidente Prudente, foi o primeiro estabelecimento de ensino médio da Capital da Alta Sorocabana e durante alguns anos foi o único estabelecimento de ensino médio no círculo de $300 \mathrm{~km}$ compreendendo uma dezena de munícipios (LITHOLDO, 1984, p.16).

Em 1937, o Ginásio São Paulo foi comprado pelos professores Luiz Barbosa de Oliveira e Oduwaldo Souza Frota. Boulanger, o antigo proprietário, teve que vender o prédio devido dificuldades financeiras. Em 1939, Luiz Barbosa de Oliveira e Oduwaldo Souza Frota também venderam o estabelecimento para Akiko Nishi Chiva, pelo mesmo motivo, ou seja, necessidades financeiras (LITHOLDO, 1984).

Em 1939, “(...) a rêde estadual de ensino médio contava com menos de 20 ginásios oficiais. Presidente Prudente era, então, ainda uma menina de 22 anos e, (...) possuía tãosomente um único ginásio, e particular: o Ginásio São Paulo com cursos diurnos apenas" (LITHOLDO, 1984, p.35). Nessa época, jovens reivindicaram a criação de um ginásio público e para isso, envolveram Domingos Leonardo Cerávolo que era prefeito da cidade (LITHOLDO, 1984).

Em 29 de outubro de 1939, o prefeito de Prudente/SP, convocou uma reunião em que o objetivo era tratar da construção do Ginásio do Estado de Presidente Prudente/SP. Em 13 de novembro de 1939, o coronel Goulart propôs a aquisição do terreno para que ocorresse a construção do ginásio, sendo escolhido:

(...) um terreno de propriedade do próprio coronel Goulart, situando na Avenida Antônio Prado (hoje Av. Washington Luíz). Media o terreno 88 metros de frente por 110 de fundo. Foi avaliado em 50 contos de réis, sendo que o proprietário daria 20 contos de réis, faltando portanto apenas 30 contos para que o terreno fosse adquirido (LITHOLDO, 1984, p.42).

Periódico Horizontes - USF - Itatiba, SP - Brasil - e019049 
Em 1940, o Interventor Federal do Estado, Adhemar Pereira de Barros, estabeleceu condições para o funcionamento do ginásio, a saber: construção de acordo com planta da secretaria da viação e obras públicas e material didático e pedagógico do ensino secundário (LITHOLDO, 1984). Assim, teve início “(...) uma intensa campanha na cidade, com solicitação de auxílio de firmas comerciais. Em julho do mesmo ano a campanha já havia atingido a cidade de Presidente Wenceslau" (LITHOLDO, 1984, p.43).

Em 1940, o Conselho Fiscal da Obra da construção do ginásio comprou o terreno para construção do estabelecimento no valor de 3:737\$500 de Sisa (Imposto de transmissão) (LITHOLDO, 1984). É importante mencionar que o terreno pertencia a prefeitura de Presidente de Prudente/SP.

Com a compra do terreno, era necessário a verba para que fosse construído um ginásio; essa verba resultou de atividades na cidade, como um baile de carnaval em que foram arrecadados 70 contos de réis. Com isso, em novembro de 1940, iniciou-se a construção, que teve como engenheiro um funcionário da prefeitura da cidade.

Antes da construção do prédio de Hélio Ayres, foi realizada a instalação do Ginásio do Estado (LITHOLDO, 1984). Dessa forma, o Ginásio Estadual de Presidente Prudente/SP teve sua construção iniciada em 1940 e em 1941, foi instalado o Ginásio do Estado da cidade de Presidente Prudente/SP (RESENDE, 2012):

(...) pelo Decreto-Lei 11.864, foi criado o GINÁSIO ESTADUAL DE PRESIDENTE PRUDENTE. E em 23 de abril de 1941, (...) o Ginásio foi solenemente instalado. Assim surgiu o Ginásio Estadual de Presidente Prudente, mais pelo esforço e iniciativa dos habitantes de Prudente do que por outra circunstância qualquer (LITHOLDO, 1984, p.44-45).

Em 1942, havia uma parte do ginásio construída “(...) podendo o prédio ser inaugurado" (LITHOLDO, 1984, p.44). Assim, como não havia prédio próprio, inicialmente, o Ginásio Estadual funcionou no prédio do Grupo Escolar "Prof. Adolpho Arruda Mello".

Para diretor do ginásio foi nomeado o professor João Miguel do Amaral “(...) o qual fixou para o dia 29 de abril [de 1941] os exames de admissão. Compareceram 29 candidatos, sendo aprovados 20" (LITHOLDO, 1984, p.45). Em 1941, houve alunos do Colégio São Paulo que transferiram seus estudos para o Ginásio Estadual, e, assim, de 29 alunos, o ginásio passou a ter 
45 alunos. Para atender esses alunos, houve o funcionamento de duas classes de primeiras séries no prédio do Grupo Escolar "Prof. Adolpho Arruda Mello" (LITHOLDO, 1984).

A criação do Ginásio Estadual de Prudente/SP “(...) provocou certa concorrência ao Ginásio São Paulo, havendo mesmo algum atrito entre seu diretor, o Dr. Francisco Marsiglia [advogado], e o então diretor do Ginásio Estadual Oficial” (LITHOLDO, 1984, p.32).

Os alunos do Ginásio Estadual utilizavam uniformes e cadernetas em que estavam relatados aspectos das suas vidas escolares, esses relatos tinham início com os exames de admissão (ARAUJO, 1995). O autor também menciona que no Ginásio Estadual o estudo era mais difícil do que no Ginásio São Paulo que era particular e

Com a Reforma Capanema ${ }^{10}$ foi abolida a $5^{a}$ série e estabelecidas as seguintes disciplinas no curso ginasial: Português, Latim, Francês, Inglês, Matemática, Ciências Naturais, História Geral, História do Brasil, Geografia Geral, Geografia do Brasil, Trabalhos Manuais, Desenho, Canto Orfeônico (ARAUJO, 1995, p.44).

Em 1941, especificamente em julho, com o interventor Federal de São Paulo, passando a ser Fernando de Souza Costa, o prédio em que funcionava o Ginásio Estadual foi ameaçado de ter que encerrar suas atividades devido precárias instalações, entretanto “(...) em março de 1942, o Ginásio, passou a funcionar em seu prédio próprio, com as cinco séries ginasiais" (LITHOLDO, 1984, p.47).

Nesse estabelecimento, em 1943, através do “(...) Decreto no 13.543, de 9/9/1943, foi criado o Curso Colegial, no governo de Fernando Costa. (Daí se origina o nome do estabelecimento de ensino.) (...) o Curso Colegial começou a funcionar no dia 15/3/1945" (LITHOLDO, 1984, p.47). Em 1952, no Ginásio Estadual foi criado o Curso Ginasial noturno que funcionou em 1953.

Assim, o Ginásio Estadual tornou-se Colégio do Estado e, em 1953, tornou-se Instituto de Educação "Fernando Costa” “(...) criado por lei no 2.337, de 20/10/1953. Foi instalado em março de 1954, porém seus cursos só vieram a funcionar em 1955. Em 1954, funcionava apenas, o curso

\footnotetext{
${ }^{10}$ Essa reforma ocorreu a partir de 1942, “[...] compôs o ensino com cinco anos de curso primário, quatro de curso ginasial e três de colegial, este último podendo ser ofertado na modalidade clássico ou científico. O ensino colegial perdeu o caráter propedêutico, preparatório para o ensino superior e passou a se preocupar com a formação geral." (FERREIRA, 2012, p.104).
}

Periódico Horizontes - USF - Itatiba, SP - Brasil - e019049 
de Aperfeiçoamento" (LITHOLDO, 1984, p.61).

Araujo (1995, p.59) também afirma que:

Até 1953 o antigo Ginásio do Estado, como eram chamados popularmente as instituições estaduais, chamou-se Colégio e Escola Normal Dr. Fernando Costa. Foi neste ano que o antigo ginásio estadual ganhou o nome pelo qual é conhecido até os dias de hoje: Instituto de Educação Fernando Costa.

No IE "Fernando Costa" havia um ensino que era “(...) científico, literário e artístico. (...) Foi o centro educacional e intelectual da Prudente dos anos 40, 50 e início de 60. Preparou professores" (RESENDE, 2012, p.65). Em relação ao terreno desse estabelecimento, Litholdo (1984, p.61) afirma que a:

(...) área total do terreno do Instituto de Educação Fernando Costa, medindo $9.680 \mathrm{~m}^{2}$, foi adquirida por doação da prefeitura pela Lei 2.032, de 24/12/1952. A escritura de doação foi lavrada em 15/3/1953 no 20 Tabelionato de São Paulo. O imóvel foi então avaliado em seis milhões quinhentos mil cruzeiros.

Em 1952, o governador do estado de São Paulo, Lucas Garcez, promulgou a autorização para a Prefeitura da cidade de Presidente Prudente/SP, adquirir

(...) por doação, o imóvel localizado no perímetro urbano daquela cidade, constituído de terreno, edifícios e demais benfeitorias, onde funciona o Colégio Estadual e Escola Normal "Dr. Fernando Costa", a saber: Um terreno de forma regular, com a área de $9.680 \mathrm{~m}^{2}$ (nove mil, seiscentos e oitenta metros quadrados), medindo $88 \mathrm{~m}$ (oitenta e oito metros) de frente por $110 \mathrm{~m}$ (cento e dez metros) da frente aos fundos, confrontando pela frente com a Avenida Conselheiro Antonio Prado, de um lado com a rua Ribeiro de Barros, de outro com a rua Cel. José Soares Marcondes e pelos fundos com própriedade de Dante Vicentini e Antonio de Oliveira Rachado (SÃO PAULO, 1952, p.2).

Esse terreno, mencionado, doado pela prefeitura, é o mesmo que Goulart propôs em 1939, que fosse comprado, com isso, foi o terreno em que funcionou Ginásio Estadual de Presidente Prudente/SP.

Em 1954, teve início a construção da segunda parte do prédio que foi entregue em 1965 (LITHOLDO, 1984). O Curso Normal foi implantado no IE "Fernando Costa", e após anos “(...) o 
Curso Normal também começou a funcionar no Colégio São Paulo (...)" (RESENDE, 2006, p.177).

O número de alunos matriculados no Curso Ginasial aumentou-se com o passar dos anos, como é possível verificar com Litholdo (1984) que menciona que em 1937, foram matriculados 36 alunos no Curso Ginasial; em 1938, 129 alunos; em 1939, 149 alunos; em 1940, 188 alunos; e em 1941, 240 alunos. Como crescia o número de alunos do Curso Ginasial, em 1964, surgiu a primeira extensão do Instituto de Educação "Fernando Costa" no prédio do Grupo Escolar "Marieta Ferraz de Assumpção". Também foram instaladas nesse ano duas extensões no prédio da Academia "Joaquim Murtinho" e outra no prédio do quarto grupo escolar coronel "José Soares Marcondes". Em 1965, foi instalada a extensão que funcionou no prédio "João Francisco Godoy" (LITHOLDO, 1984).

Em relação aos diretores do IE "Fernando Costa" considerando o ano de criação até o ano de 1971, teve-se: João Miguel do Amaral, José Leite Carvalhaes, Henrique Antonio Ribeiro, Marta Maria Santana Costa, João Bohac, Wlademir Bittencourt de Carvalho, Luiz Carvalho Gomes e Krisan Martin (LITHOLDO, 1984).

No dia quatro de novembro de 1968, professores, diretores e inspetores se reuniram no IE "Fernando Costa" para tratar das extensões desse IE que se transformaram em ginásios e colégios. Assim, foram tratados que as extensões instaladas no prédio do Grupo Escolar: "Franco Godoy", no "Marietta Ferraz de Assumpção", no "Cel. José Soares Marcondes", no "Antonio Fioravante de Menezes" e no colégio "Joaquim Murtinho", tinham sido extintas no mês anterior e “(...) estavam criados os ginásios correspondentes às extensões” (LITHOLDO, 1984, p.87).

A partir de 1976, “(...) o Instituto de Educação Fernando Costa deixou de ter 1ํ Grau, passando a chamar-se Escola Estadual de 2ㅇ Grau Fernando Costa, conforme Resolução SE-23/01 no DOE em 24/04/1976." (LITHOLDO, 1984, p.62). Araujo (1995) também afirma que depois de 1976, o IE “Fernando Costa” passou a ser Escola Estadual de 2o grau. Além disso, afirma também que nessa escola, a maioria dos professores vieram da USP e utilizavam os métodos da Escola Nova (ARAUJO, 1995). Atualmente, o prédio em que funcionou o IE "Fernando Costa" é uma Escola Estadual (E.E.), denominada de E.E. "Fernando Costa" e atende do sexto ano do Ensino Fundamental ao terceiro ano do Ensino Médio.

\section{Exterior do prédio do Instituto de Educação "Fernando Costa"}

Periódico Horizontes - USF - Itatiba, SP - Brasil - e019049 
Em relação às Instituições Educativas, Magalhães (2004, p.144) afirma que a:

(...) disposição arquitetônica dos prédios, a distribuição e ordenação dos espaços, a orientação estética, a acessibilidade influenciam o cotidiano educacional, quanto à materialidade e à funcionalidade, mas também afetam as representações e os modos de estar, vivenciar, relacionar-se, referenciar e projetar por parte de todos os membros de uma comunidade educativa.

Magalhães (2004, p.142), também afirma que há instituições em prédio de origem e instituições em prédios adaptados e ao se observar essas instituições devem-se considerar alguns aspectos

(...) como localização, projeção e plano arquitetônico, processo de licenciamento, enquadramento paisagístico e urbanístico e tipo de construção, organização dos espaços, estado de conservação, adaptações arquitetônicas e espaciais. A implantação do edifício na paisagem física e humana, os acessos e formas de isolamento e/ou de relação refletem, condicional ou estimulam a relação com a comunidade envolvente.

Além disso, "(...) se pode perguntar como e em que circunstâncias foram feitas as obras de conservação, ampliação, reajustamento dos prédios. Nos processos de construção, como nos processos de adaptação, não deixa de haver áreas pedagógico-didáticas prioritárias." (MAGALHÃES, 2004, p.143).

O prédio em que funcionou o Instituto de Educação "Fernando Costa", como mencionei, atualmente, é uma escola estadual. Ao consultar o arquivo permanente ${ }^{11}$ dessa escola, veriiquei que esse prédio está localizado na área urbana central de Presidente Prudente/SP, que está próximo ao teatro, à Prefeitura Municipal e ao centro comercial da cidade, demonstrando que o prédio foi construído em uma área de evidência, ou seja, visibilidade.

\footnotetext{
11 O termo "arquivo permanente" (comumente denominado de "Arquivo morto") é baseado na "Teoria das três idades" da ciência da informação, de acordo com essa teoria os arquivos "[...] são considerados arquivos correntes, intermediários ou permanentes, de acordo com a frequência de uso por suas entidades produtoras e a identificação de seus valores primário e secundário." (ARQUIVO NACIONAL, 205, p.160, grifo do autor), dessa forma, compreendese arquivo corrente os consultados frequentemente, os arquivos intermediários são consultados com menos frequência e os permanentes constituem-se em um conjunto de "[...] documentos preservados em caráter definitivo em função do seu valor. [...] Também chamado de arquivo histórico.” (ARQUIVO NACIONAL, 205, p.34).
}

$$
\text { Periódico Horizontes - USF - Itatiba, SP - Brasil - e019049 }
$$




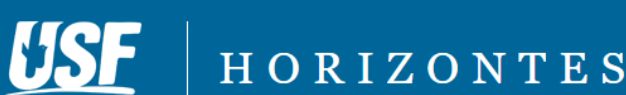

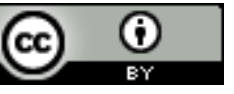

Além de possibilitar a visibilidade, o prédio em que foi instalado o IE "Fernando Costa" abrange um quarteirão inteiro da da Washington Luís, avenida da cidade de Presidente Prudente/SP, conforme é possível visualizar na imagem abaixo:

Figura 1- Imagem panorâmica do Instituto de Educação "Fernando Costa"

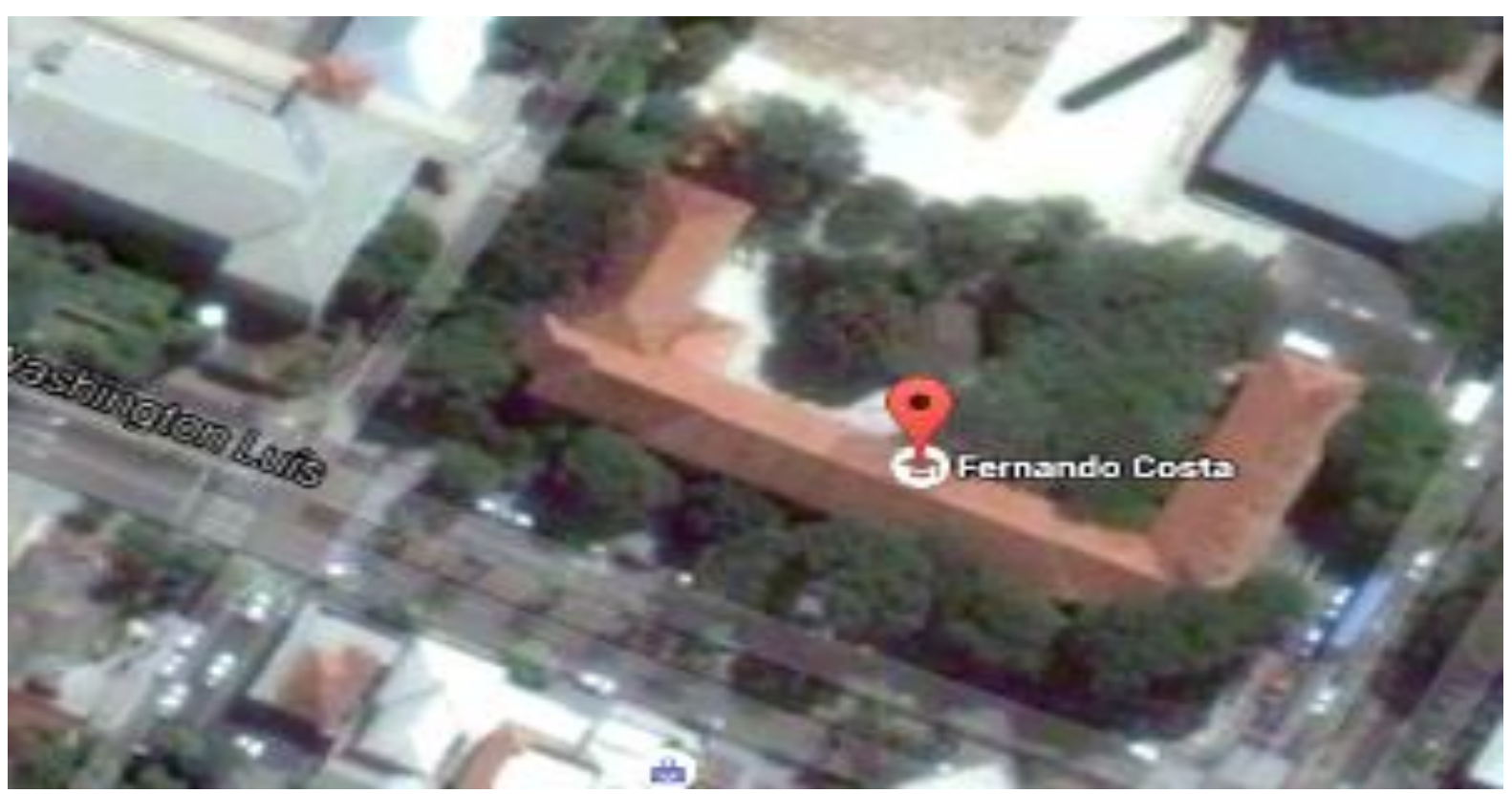

Fonte: google maps ${ }^{12}$

Esse fato, demonstra que o prédio que ocupou o IE "Fernando Costa" representa uma grande configuração arquitetônica. Segundo Carvalho (2011) o modelo escolar paulista republicano se relaciona com “(...) uma pedagogia, uma política e uma estratégia de formação docente articulada segundo uma lógica regida pelo 'primado da visibilidade." (CARVALHO, 2011, p.185), primado que é possível constatar com a dimensão do prédio que ocupou o IE em questão.

Vidal e Faria Filho (2005) ao relatarem sobre os espaços escolares do ensino primário no Brasil, mencionam que foram organizados em três configurações: casas-escola, escolasmonumento e escolas-funcionais. Apesar de este texto estar relacionado com o ensino secundário, é possível constatar aspectos das escolas-monumentos contidos no prédio do IE "Fernando Costa", considerando que por meio das escolas-monumentos buscava-se "(...) dar a

12 Disponível em: < https://www.google.com.br/maps/search/Washington+Luiz+maps+Presidente+Prudente/@ 22.120253,-51.3893069,359m/data=!3m1!1e3>. Acesso em: 31 jul. 2015.

Periódico Horizontes - USF - Itatiba, SP - Brasil - e019049 
ver a própria República e seu projeto educativo exemplar e, por vezes, espetacular. Não era casual, que as edificações escolares iniciadas em São Paulo, nos anos de 1890 (...) visassem à monumentalidade" (VIDAL; FARIA FILHO, p.52).

Nas escolas-monumentos, dentre os aspectos possíveis de serem vistos, destaca-se “(...) o convívio com a arquitetura monumental, os amplos corredores (...) as dimensões grandiosas de janelas e portas, (...) o destaque do prédio escolar em relação à cidade que o cercava e visavam incutir nos alunos o apreço à educação racional e científica (...)"(VIDAL; FARIA FILHO, p.54). Nos anos de 1950 e 1960, os prédios escolares em lugar dos grandiosos prédios construídos no início da República, com a “(...) a luta da democratização da escola (...) [passaram a serem construídos como] prédios funcionalistas (...)" (VIDAL; FARIA FILHO, p.68).

Em relação ao prédio do IE "Fernando Costa" verifica-se que apesar do prédio ser comprido, ocupa apenas a frente e as laterais do terreno, ou seja, ocupa principalmente a parte que possibilita a visualização externa. Atualmente, a parte central desse terreno é o pátio da E.E. "Fernando Costa".

Na década de 40, quando esse prédio foi construído para instalar o Ginásio Estadual de Prudente/SP, que posteriomente, como mencionei, se transformou no IE "Fernando Costa", a fachada era similar a atual, como se pode visualizar nas imagens abaixo:

Figura 2: Prédio do Instituto de Educação "Fernando Costa" na década de 40

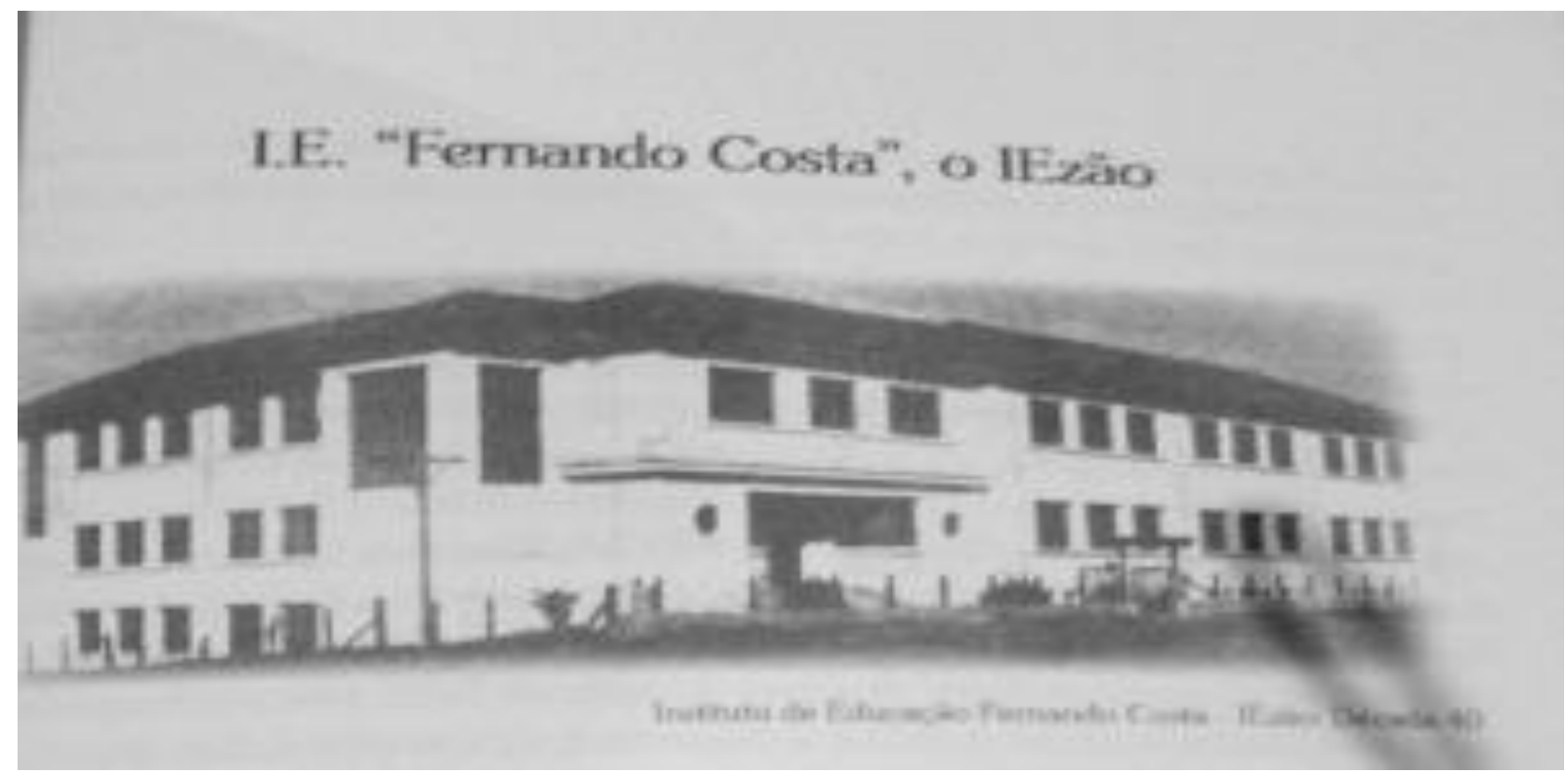

Fonte: Raízes Prudentinas 3 (RESENDE, 2012, p.65).

Periódico Horizontes - USF - Itatiba, SP - Brasil - e019049 
Figura 3a: Prédio do Instituto de Educação “Fernando Costa” atualmente

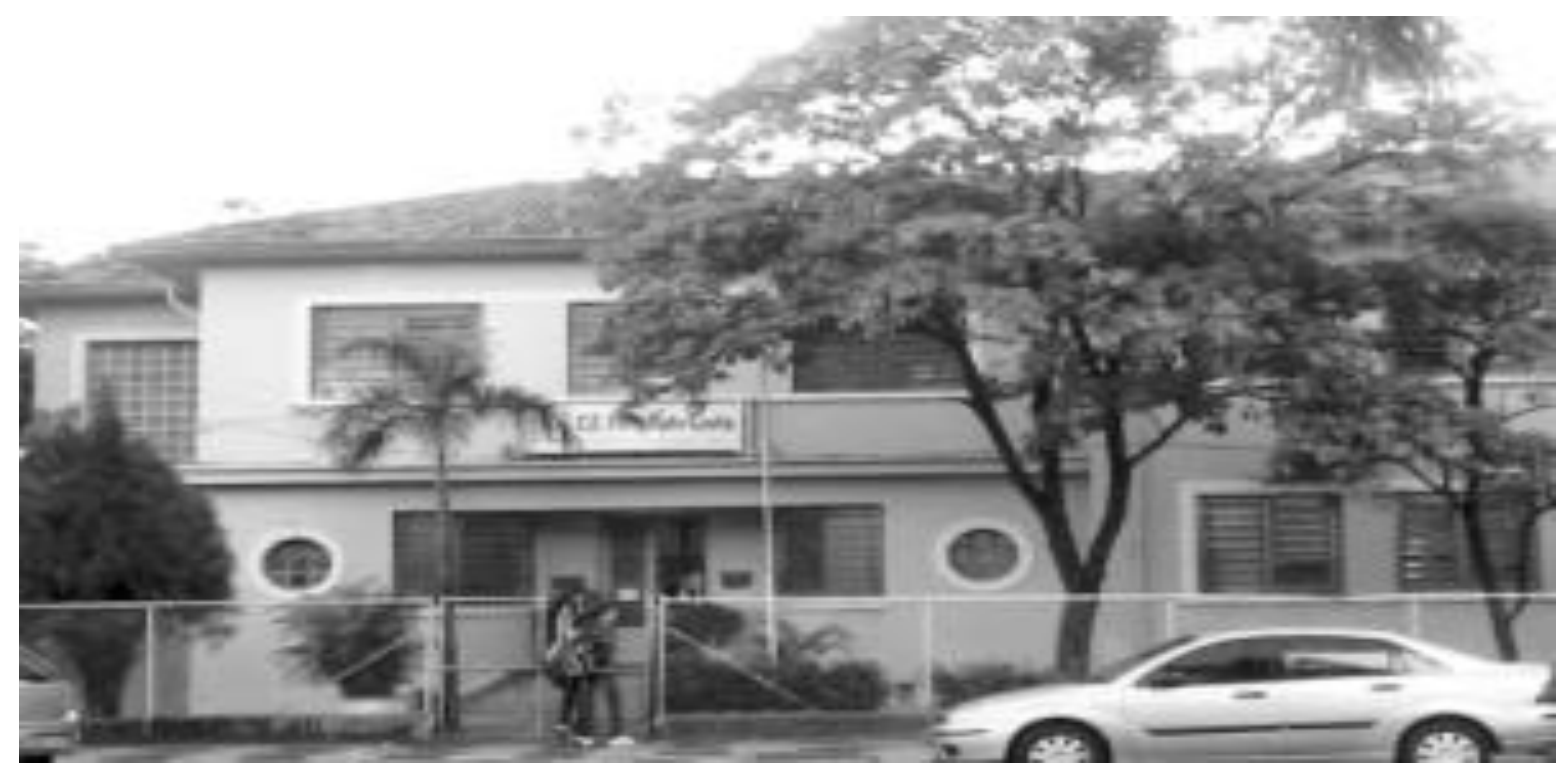

Fonte: google maps ${ }^{13}$

Figura 3b: Prédio do Instituto de Educação "Fernando Costa" atualmente $51.3878549,3 a, 75 y, 90 t /$ data $=$ !3m8!1e2!3m6!1syGULWPChvo\%2FUOSHL58Lw9I\%2FAAAAAAAAALE\%2FYBmCYsiDkmU!2e4!3e12!6s\%2F\%2Flh3.googleusercontent. com\%2F-6yGULWPChvo\%2FU0SHL58Lw9I\%2FAAAAAAAAALE\%2FYBmCYsiDkmU\%2Fs203-kno\%2F!7i640!8i480!4m2!3m1!1s0x9493f5b4c411d3d1:0xf044b295575281c5!6m1!1e1. Acesso em: 31 jul. 2015.

Periódico Horizontes - USF - Itatiba, SP - Brasil - e019049 


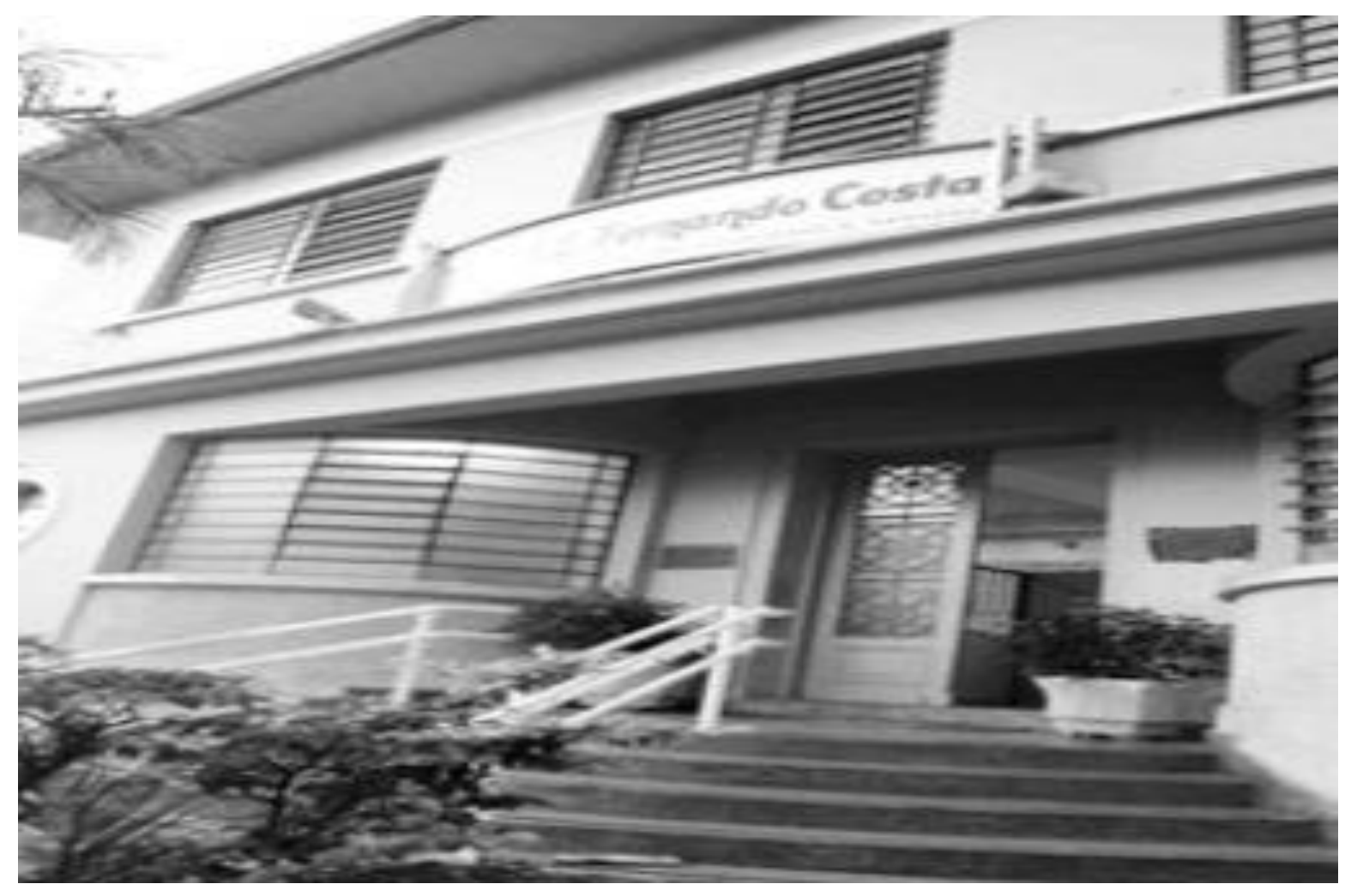

Fonte: acervo da autora

Constata-se o predomínio dos espaços retílineos, sendo a estrutura inicial do Ginásio Estadual construída, mantida. É importante considerar que o espaço é educativo, ele tem sigificado para o currículo e esse espaço está sempre relacionado com o tipo de ensino, considerando que os espaços de educação infantil são menores que os espaços dos níveis universitários (FRAGO, 2001).

A fachada da instituição, não é externa, mas pertence a instituição, pois o que é externo refere-se à rua, praça etc. (BENCOSTTA, 2001). Pensando na instituição em questão, houve alteração na fachada com o nomenclatura atual da instituição e grade diferente da antiga na entrada, além de haver árvores na frente da escola. Sendo que o elemento decorativo da fachada do IE "Fernando Costa" consiste na porta e em duas janelas em formato circular.

Destaco que as IEs podem ser analisadas a partir da relação entre o externo e o interno, o aberto e o fechado. Como mencionou Frago (2001) há diversos modelos arquitêtonicos das Instituições Educativas e o relacionado ao IE "Fernando Costa", é o em U, considerando que nesse modelo, há a predominância da fachada da instituição. O contrário desse modelo, no 
modelo em U invertido, há a predominândia do pátio ou o jardim da institituição; nesse modelo passa a reprentação de acolhimento, proteção ao visitante que é recebido na instituição“(...) entre suas duas asas como se fossem braços" (FRAGO, 2001, p.97).

É possível observar que ao visualizar a fachada do prédio do IE "Fernando Costa", em um primeiro momento e aparentemente que ela é constituída de dois andares, todavia ao visualizar a escola em diagonal, como na figura 2, visualiza-se três andares de janelas, o que possibilita a consideração que havia três andares nesse prédio.

O prédio em questão, realmente, tem três andares, mas a portaria, ou seja, a porta de acesso a entrada do prédio está no segundo andar. Em relação a porta de acesso de entrada do prédio, podemos visualizar de acordo com a figura $3 \mathrm{~b}$, que para se ter o acesso é necessário passar por uma escada que possibilita a impressão de que se está subindo ao entrar na escola. É importante ressaltar que essa impressão aumenta ao constatar-se que se está no segundo andar ao entrar nesse prédio.

Dessa maneira, o prédio em que ocupou o IE "Fernando Costa" representa a grandiosidade iniciada pela fachada da escola que ocupa um quarteirão de um terreno localizado no centro da cidade de Presidente Prudente/SP e finalizando com três andares, sendo a entrada presente no segundo andar e com acesso realizado a partir de escadas, sendo que essas representam a visibilidade de "subir" ao entrar nesse IE.

\section{Interior do prédio do Instituto de Educação "Fernando Costa"}

Em relação ao interior do prédio do IE "Fernando Costa" localizei uma planta. Segundo Bencostta (2001, p.116) a planta “(...) é uma potencial fonte através da qual se pode examinar a estrutura de uma obra arquitetônica.". Na planta que localizei há o "Pavimento Terreo", o "Pavimento Superior" e o "Pavimento superior do laboratorio de quimica" como é possível visualizar na figura 4 abaixo:

Figura 4- Planta do IE "Fernando Costa" 


\section{HSE H ORIZON T ES}

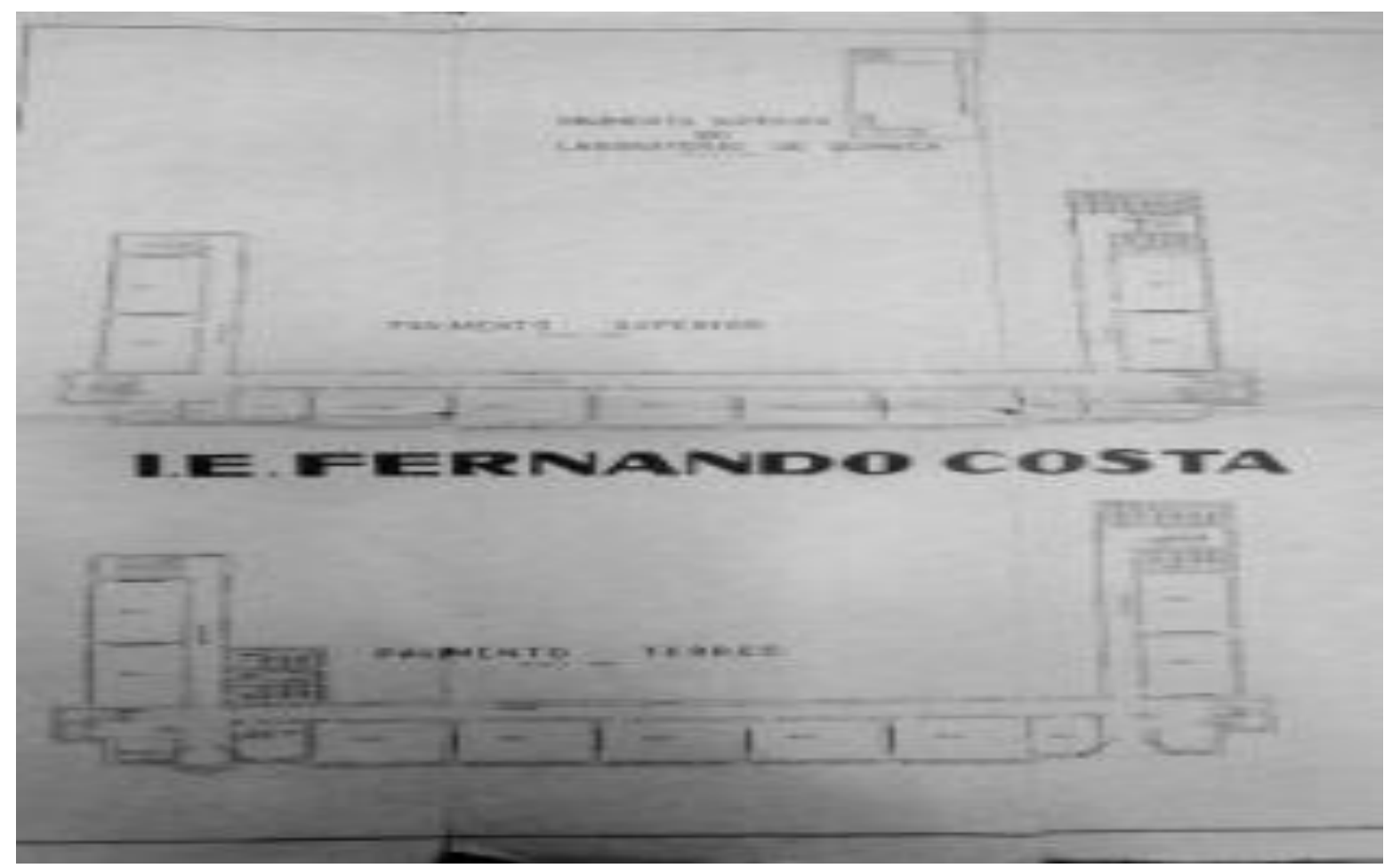

Fonte: arquivo permanente da E.E. "Fernando Costa"

A partir da visualização da planta do IE "Fernando Costa", é possível constatar que o prédio dessa instituição é composto por dois braços assimétricos que partem do espaço central. Constata-se que apesar do prédio do IE em questão ter três andares, na planta, somente é indicado dois andares e de acordo com essa planta, é possível constatar que se refere ao 20 e 3은 andar do atual prédio que ocupa a E.E. "Fernando Costa".

Entretanto, podemos visualizar que o atual $2^{\circ}$ andar desse prédio, na planta do IE é denominado de "térreo" o que possibilita inferir que provavelmente no IE, somente eram utilizados dois andares do prédio. Abaixo, apresento a planta do denominado térreo do IE "Fernando Costa".

Figura 5- Planta do "Pavimento terreo" do IE "Fernando Costa" 


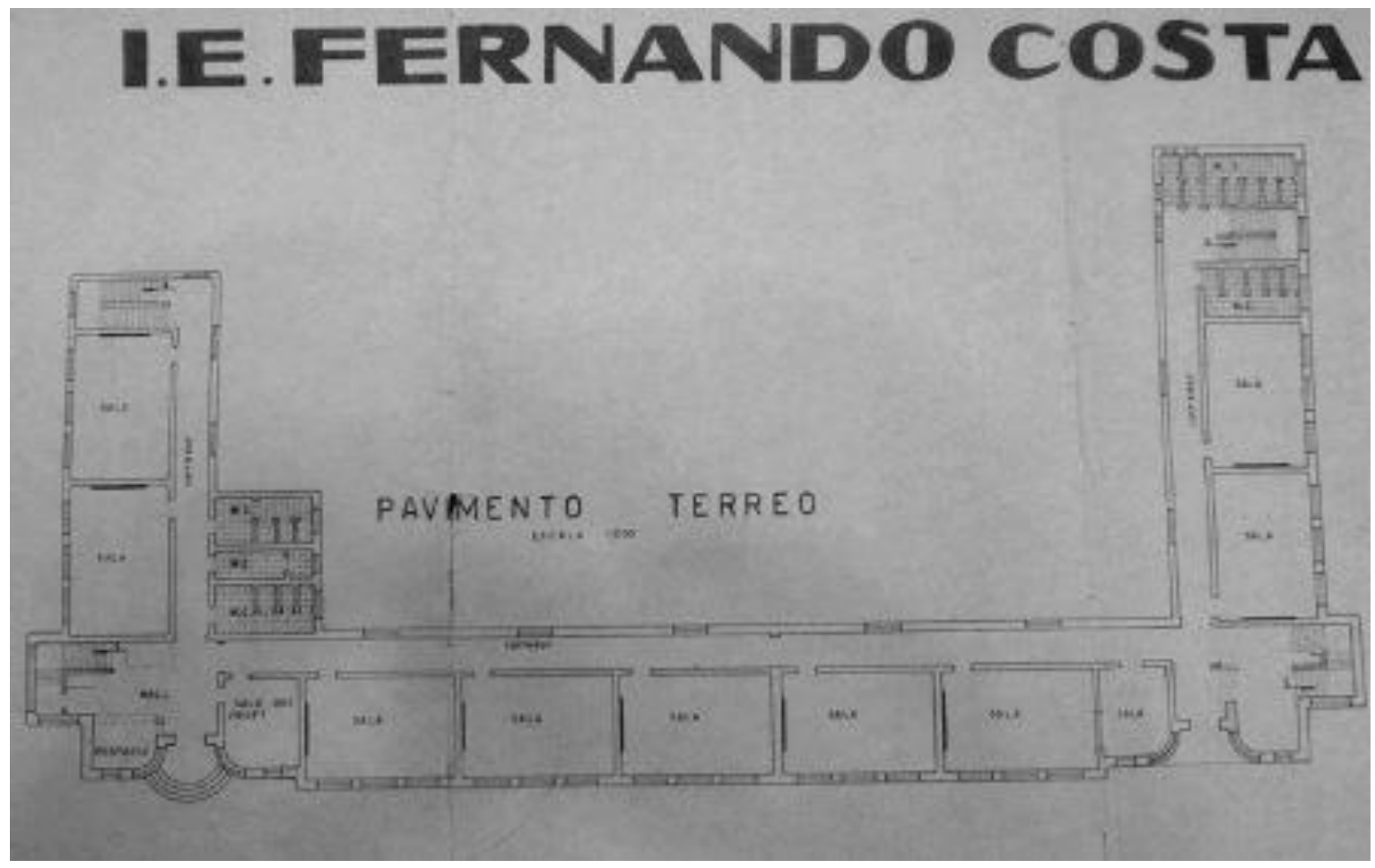

Fonte: arquivo permanente da E.E. "Fernando Costa"

Magalhães (2004), afirma que as Instituições Educativas possuem dois tipos de área organizacional: a pedagógica e a didática (em que há a relação entre professor e aluno); e a relacionada à direção e gestão (em que os professores e alunos são secundados).

A partir dessa consideração e da apresentação da figura 5 acima, considera-se que o denominado "pavimento térreo" do IE "Fernando Costa" consiste em um retângulo com braços fechados, a entrada denominada de "portaria" está no lado esquerdo do prédio. O plano arquitetônico mostrado resguarda a parte interna da instituição, ou seja, resguarda a área destinada ao aspecto pedagógico.

Ao entrar no prédio, tem-se acesso a um corredor que passa por duas salas e três banheiros, do lado esquerdo da entrada há o "hall" e no lado direito havia a sala dos professores. O corredor é reto e de acordo com Frago (2001, p.109) “(...) os corredores têm de ser retos e não curvos, pois em tal caso não se poderia vigiar. Essa é a razão funcional dessa disposição".

Ao lado da sala dos professores havia seis salas, sendo a sexta de tamanho menor que as demais, o acesso a essas salas ocorria através de um corredor. Ao lado da sexta sala tem-se outro "hall" seguido por um corredor, duas salas e dois banheiros. Assim, no IE "Fernando Costa" havia 


\section{HSF HORIZON TES}

DOI: https://doi.org/10.24933/horizontes.v37i0.750

10 salas sendo duas do lado direito, duas do lado esquerdo e seis salas cujas janelas constituem a fachada da escola.

Com o IE "Fernando Costa" é possível verificar o que foi defendido por Frago (2001, p.107) que “(...) parece claro o predomínio geral do retilíneo sobre o redondo ou curvilíneo, assim como dos retângulos e quadrados sobre os círculos, espirais ou elipses".

Figura 6- Planta do "Pavimento superior" do IE "Fernando Costa"

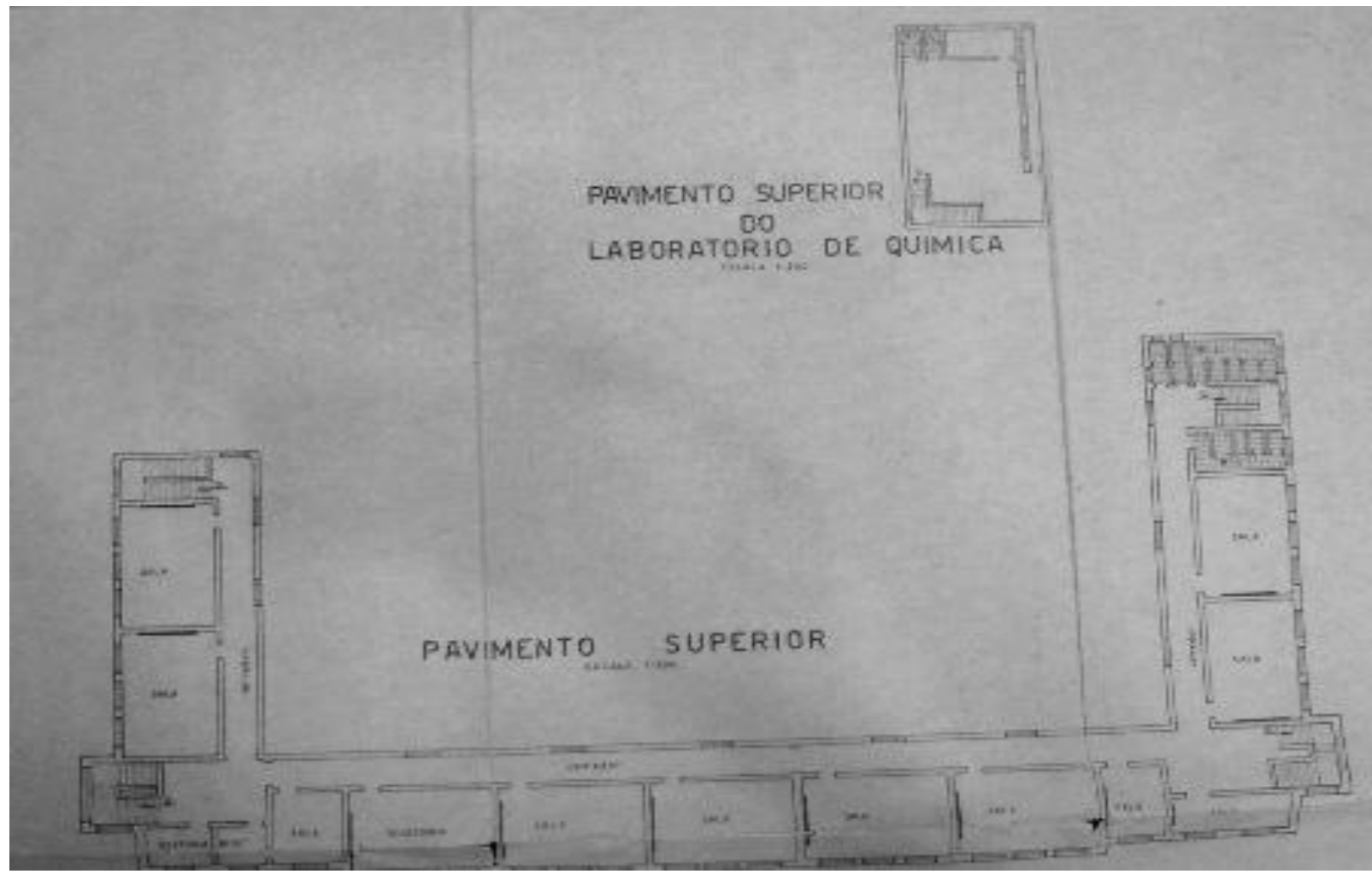

Fonte: arquivo permanente da E.E. "Fernando Costa"

O "Pavimento superior" do IE "Fernando Costa" também tem formato de um retângulo com braços fechados, ao lado esquerdo do prédio havia duas salas, a diretoria, a biblioteca, outra sala, a secretaria, ao lado da secretaria havia seis salas, sendo que as duas últimas são menores que as demais. Seguindo a esquerda há duas salas e dois banheiros.

Constata-se que de acordo com a planta do IE "Fernando Costa" a diretoria localiza-se no último andar do IE, distante da portaria e próxima ao acesso para o andar inferior e a biblioteca, ou seja, é possível constatar que a sala da direção posicionava-se relativamente distante das salas de aula.

Periódico Horizontes - USF - Itatiba, SP - Brasil - e019049 
A figura da sala do diretor central, entre as salas, facilitava a inspeção do onipresente vigilante. Segundo Frago (2001, p.114) a localização da sala do diretor reflete a concepção “(...) dessa figura e suas funções, em outras palavras, a relação que de um modo geral existe entre a estrutura ou a disposição espacial da escola".

O diretor na área central da instituição tinha a função de vigiar os professores, todavia, quando o diretor representa a comunidade externa e se torna responsável pelos serviços administrativos e pedagógicos, a sala dele tende a se localizar na entrada do edifício próximo a secretaria (FRAGO, 2001). No caso do IE "Fernando Costa" a sala do diretor estava presente próximo à secretaria, o que pode demonstrar o destaque da responsabilidade com os serviços administrativos.

Em relação à sala de aula do IE "Fernando Costa", pode-se constatar que está de acordo com o afirmado pelo Frago (2001, p.117) “(...) a sala de aula é um compartimento em geral retangular, fechado (...)" As salas retangulares favorecem o ensino frontal e “(...) é no âmbito da sala de aula, o núcleo por excelência da atividade instrutiva, onde a análise histórica mostra essa relação entre a disposição no espaço das pessoas e objetos que nelas estão, e o sistema ou método de ensino seguido" (FRAGO, 2001, p.121).

Em uma parte superior da planta do IE "Fernando Costa" há a planta do laboratório de química como é possível verificar na figura 6. Nessa planta, com formato retangular, há a descrição de dois banheiros. Outro aspecto interno do IE em questão é a escada de acesso para os demais andares. É importante mencionar que no final do lado esquerdo e do lado direito do prédio, as escadas somente possibilitam o acesso entre os segundos e terceiros andares. As escadas com acessos para o primeiro andar estão localizadas em uma parte central do prédio com pouca visibilidade e não próximo ao "hall" em que há a escada de acesso ao terceiro andar.

A partir da utilização do Inventário Geral dos bens móveis do Instituto de Educação Fernando Costa Presidente Prudente (SECRETARIA..., 1965), é possível confirmar que em 1965, no IE "Fernando Costa" havia a "diretoria", a "secretaria", o "saguão superior", "saguão inferior", a "sala da biblioteca", a "sala de educação física", a "sala dos professôres", a "salas de aula", as "salas de trabalhos manuais", a "cantina", o laboratório e a "sala de jardim de infância". Assim, constata-se novamente que somente eram utilizados dois andares ("saguão superior" e "saguão inferior") no prédio em que funcionou o IE "Fernando Costa". 
Dessa forma, no geral, é possível verificar que no prédio em que funcionou o IE "Fernando Costa" há o predomínio do retílineo, andares e escadas. Além das salas de aula, havia uma sala para os professores localizada próxima a entrada do prédio, enquanto que a diretoria, a biblioteca e a secretaria estavam distantes da entrada, o que pode demonstrar que as atividades dos diretores estavam mais relacionadas com os serviços administrativos.

É possível constatar também o defendido por Frago (2001, p.91):

(...) a arquitetura escolar combinou a clausura ou encerramento com a acentuada ostentação de um edifício sólido cujas paredes constituíam a fronteira com o exterior ou que se achava separado desse exterior por uma zona mais ou menos ampla do campo escolar e um muro ou grade que assinalava os limites do espaço reservado.

Ou seja, no IE "Fernando Costa", havia uma ostentação no prédio que separava seus espaços com muros, inserindo fronteiras com o exterior.

\section{Considerações finais}

Segundo Magalhães (2004) na análise do espaço da Instituição Educativa, pode-se analisar o desenho ou forma, acomodações, dimensões, valores, materiais, elementos simbólicos, referenciais incorporados ou percebidos nesse espaço. Apesar de não ter sido possível realizar todas essas análises, foi possível constatar que o prédio em que funcionou o extinto Instituto de Educação "Fernando Costa", ou seja, o espaço em que foi priviliegiada a formação de professores, foi comprado pela prefeitura de Presidente Prudente/SP, em 1940, para construção do Ginásio Estadual da cidade e em 1953, ano em que houve a instalação do Instituto de Educação "Fernando Costa" na cidade de Presidente Prudente/SP, esse prédio foi doado para o Estado.

Assim, constata-se que apesar do prédio dessa IE não ter sido construído exclusivamente para ocupar o IE "Fernando Costa", ele foi construído para ocupar uma determinada Instituição Educativa. É importante considerar que “(...) a instituição escolar e o ensino só merecem esse nome quando se localizam ou se realizam num lugar específico. E, com isso, quero dizer num lugar especificamente pensando, desenhado, construído e utilizado única e exclusivamente para

Periódico Horizontes - USF - Itatiba, SP - Brasil - e019049 
esse fim." (FRAGO, 2001, p.69).

O prédio em que funcionou o IE "Fernando Costa" representa a grandiosidade, é um prédio que proporciona a visibilidade, iniciando pela fachada da escola que ocupa um quarteirão inteiro de um terreno localizado no centro da cidade de Presidente Prudente/SP e finalizando com andares, escadas e com o predomínio do retílineo.

Por fim, é importante ressaltar que a “(...) escola é espaço e lugar. Algo físico, material, mas também uma construção cultural que gera 'fluxos energéticos'." (FRAGO, 2001, p.77), essa "construção cultural" é possível verificar com as diversas utilizações do mesmo espaço, pois enquanto no IE a secretaria e a diretoria se localizavam no último andar, atualmente, na E.E. "Fernando Costa", que ocupa o mesmo prédio em que funcionou o IE em questão, a secretaria está na entrada dessa instituição ao lado da sala dos diretores e dos coordenadores pedagógicos. Dessa forma, é possível constatar que no prédio em que funcionou o Instituto de Educação "Fernando Costa" os espaços “(...) assim como a energia, enquanto energia - não se cria nem destrói, apenas se transforma" (FRAGO, 2001, p.139).

\section{Referências}

ARAUJO, I. M. A fundação do Primeiro Ginásio Estadual de Presidente Prudente: Fernando Costa. Presidente Prudente, 1995.

BENCOSTTA, M. L. A. Arquitetura e espaço escolar: reflexões acerca do processo de implantação dos primeiros grupos escolares de Curitiba (1903 - 1928). Educar, Curitiba, n.18, p.103-141, 2001. Disponível em: http://www.scielo.br/pdf/er/n18/n18a08.pdf. Acesso em: 13 jul. 2015.

BENCOSTTA, M. L. A. Memória e cultura escolar: a imagem fotográfica no estudo da escola primária de Curitiba. História, São Paulo, v.30, n.1, p.397-411, jan/jun.2011. Disponível em: http://www.scielo.br/pdf/his/v30n1/v30n1a19.pdf. Acesso em: 13 jul. 2015.

CARVALHO, M. M. C. Pedagogia moderna, pedagogia da Escola Nova e modelo escolar paulista. In: CARVALHO, M. M. C. PINTASSILGO, J. (Orgs). Modelos culturais, saberes pedagógicos, instituições educacionais: Portugal e Brasil, histórias conectadas. São Paulo: EdUSP, 2011. p.185-212.

CONCEIÇÃO, A. N. O Instituto de Educação de Presidente Prudente/SP (1953-1975): elementos para a história de uma instituição escolar. 2017. 347 f. Dissertação (Mestrado em Educação) Universidade Estadual Paulista, Faculdade de Filosofia e Ciências, Marília, 2017. Disponível em: https://repositorio.unesp.br/handle/11449/149779. Acesso em: 2 out. 2019. 
DICIONÁRIO DE ARQUITETURA. Disponível em: http://www.ebah.com.br/content/ABAAABb98AA/dicionario-arquitetura?part=2. Acesso em: 21 jul. 2015.

ENSINO: As primeiras escolas de Presidente Prudente. 2003. Disponível em: http://camarapprudente.sp.gov.br/historia/hist_oeste/cidades/pprudente/ensino.html. Acesso em: 14 jul. 2015. Não paginado.

FERREIRA, N. V. C. Educação secundária profissionalizante brasileira (1909 -1953). Rev. Hist. Edu. Latinoam, [s.n.], v.14, n.19, p.91-110, 2012. Disponível em: http://www.scielo.org.co/pdf/rhel/v14n19/v14n19a05.pdf. Acesso em: 13 jul. 2015.

FRAGO, A. V. Do espaço escolar e da escola como lugar: propostas e questões. In: FRAGO, Antonio Viñao; ESCOLANO, Agustín. Currículo, espaço e subjetividade: a arquitetura como programa. 2 ed. Rio de Janeiro: DP\&A, 2001. p.59-141.

GALERIA dos Diretores. Disponível em: http://www.fct.unesp.br/\#!/instituicao/galeria-dosdiretores. Acesso em: 10 jul. 2015. Não paginado.

GERMANO, J. W. Estado militar e educação no Brasil. 3 ed. São Paulo: Cortez, 2000.

GINZBURG, C. Sinais: raízes de um paradigma indiciário. In: GINZBURG, Carlo. Mitos, emblemas, sinais: morfologia e história. São Paulo: Companhia das Letras, 1989. p.143-179.

LABEGALINI, A. C. F. B. A formação de professores alfabetizadores nos Institutos de Educação do Estado de São Paulo (1933 a 1975). 2005. 315 f. Tese (Doutorado em Educação) - Faculdade de Filosofia e Ciências, Universidade Estadual Paulista, Marília, 2005.

LABEGALINI, A. C. F. B. A formação de professores nos institutos de educação do Estado de São Paulo (1933-1975). São Paulo: Arte e Ciência, 2009.

LITHOLDO, A. A função educacional na alta sorocabana: uma contribuição à geografia urbana: volume II. Presidente Prudente: [s.n.], 1984.

MAGALHÃES, J. P. Tecendo nexos: história das instituições educativas. Bragança Paulista: Editora Universitária São Francisco, 2004.

PAULA, R. P. et al. Presidente Prudente: uma cidade, muitas histórias. Presidente Prudente: FCT/ UNESP, 2012.

RESENDE, B. Raízes prudentinas 2. Presidente Prudente: Ed. do autor, 2006.

RESENDE, B. Raízes prudentinas 3. Presidente Prudente: Ed. do autor, 2012. 
SÃO PAULO (Estado). Lei no 2.032 de 24 de dezembro de 1952. Dispõe sôbre aquisição de imóvel, por doação. Diário Oficial do Estado de São Paulo, São Paulo, n.293, 1952. Seção III, p.2. Disponível em: http://dobuscadireta.imprensaoficial.com.br/default.aspx?DataPublicacao=195 21227\&Caderno=Poder\%20Executivo\&NumeroPagina=2. Acesso em: 12 jul. 2015.

SECRETARIA DO ESTADO DOS NEGÓCIOS DA EDUCAÇÂO. Inventário Geral dos bens móveis do Instituto de Educação Fernando Costa Presidente Prudente. Presidente Prudente, 25 ago. 1965.

SOUZA, R. F. História da organização do trabalho escolar e do currículo no Século XX: ensino primário e secundário no Brasil. São Paulo: Cortez, 2008.

VIDAL, D. G.; FARIA FILHO, L. M. Os tempos e os espaços escolares no processo de institucionalização da escola primária no Brasil. In: VIDAL, Diana G.; FARIA FILHO, Luciano M. As lentes da história: estudos de história e historiografia da educação no Brasil. Campinas: Autores Associados, 2005. p.41-72.

Recebido em março de 2019.

Aprovado em outubro de 2019. 